\title{
Fiber optic sensing technologies potentially applicable for hypersonic wind tunnel harsh environments
}

\author{
Huacheng Qiu', Fu Min ${ }^{1}$ and Yanguang Yang ${ }^{2^{*}}$
}

\author{
*Correspondence: yangyanguang@ \\ cardc.cn \\ ${ }^{2}$ China Aerodynamics Research and \\ Development Center, Mianyang \\ 621000, Sichuan Province, China \\ Full list of author information is \\ available at the end of the article
}

\begin{abstract}
Advanced sensing techniques are in big demand for applications in hypersonic wind tunnel harsh environments, such as aero(thermo)dynamics measurements, thermal protection of aircraft structures, air-breathing propulsion, light-weighted and highstrength materials, etc. In comparison with traditional electromechanical or electronic sensors, the fiber optic sensors have relatively high potential to work in hypersonic wind tunnel, due to the capability of responding to a wide variety of parameters, high resolution, miniature size, high resistant to electromagnetic and radio frequency interferences, and multiplexing, and so on. This article has classified and summarized the research status and the representative achievement on the fiber optic sensing technologies, giving special attention to the summary of research status on the popular Fabry-Perot interferometric, fiber Bragg gratings and (quasi) distributed fiber optic sensors working in hypersonic wind tunnel environment, and discussed the current problems in special optical fiber sensing technologies. This article would be regarded as reference for the researchers in hypersonic wind tunnel experiment field.

Keywords: Fiber optic sensor, Hypersonic wind tunnel, Harsh environment, Fiber optic force balance, High temperature strain sensing, High temperature sensing, Distributed sensing
\end{abstract}

\section{Introduction}

Since the 1960s, the optoelectronic techniques have been developed at a rapid pace, especially the semiconductor lasers and the optical fiber technologies, during which it is found that light wave not only could be transmitted with the optical fiber, but also could have its characteristic parameters modulated by outside physical quantities. As sensing elements, the optical fiber is able to detect multiple physical quantities. Thus, based on the various sensing principles of optical fiber, quite a few of technical solutions have been put forwards and gradually evolve into a new sensing measurement technology - optical fiber sensing technology. Fiber optic sensors have become a focus in the field of sensing technologies by right of their many advantages such as compact,

(c) The Author(s). 2020 Open Access This article is licensed under a Creative Commons Attribution 4.0 International License, which permits use, sharing, adaptation, distribution and reproduction in any medium or format, as long as you give appropriate credit to the original author(s) and the source, provide a link to the Creative Commons licence, and indicate if changes were made. The images or other third party material in this article are included in the article's Creative Commons licence, unless indicated otherwise in a credit line to the material. If material is not included in the article's Creative Commons licence and your intended use is not permitted by statutory regulation or exceeds the permitted use, you will need to obtain permission directly from the copyright holder. To view a copy of this licence, visit http://creativecommons.org/licenses/by/4.0/. 
light-weighted, high sensitivity, high multiplexing, anti-electromagnetic interference and easy to be embedded into material.

At the early stage, the intensity - modulated type fiber optic sensors took the lead of optical fiber sensing technologies [1]. Since the 1980s, the interference fiber sensors have gained the extensive attention of researchers, with interference fiber optic gyro, fiber optic hydrophone and fiber optic current transformer as representatives [2-6], and promoted the development of related optoelectronic devices. By the end of the 1980s, with the invention of fiber Bragg gratings (FBG), FBG optical fiber sensing technology has become the research focus, and meanwhile, the interference fiber optic sensing technology gets mature step by step. After 2000, the gradually matured optoelectronic elements and signal processing technologies provide researchers with how to apply various sensors, such as Fabry-Perot Interferometric (FPI) fiber optic sensors, FBG sensors, distributed fiber optic sensors, to different engineering application areas. Fiber optic sensor systems with very quick response are becoming available, with readout frequencies over $100 \mathrm{kHz}$, enabling the fiber optic sensors to operate as both static and dynamic loading sensors. This means that the fiber optic sensors enter into a practical stage. Following the development of optical fiber communication industry, the optical fiber sensing technologies become another major industry of optoelectronic technologies [7]. Among them, what are popular, in-depth researched and most promising sensors are the FPI fiber optic sensors, the FBG fiber optic sensors and the (quasi) distributed sensors based on fibers, applying to the health detection, the petrochemical engineering and the energy \& power in terms of aviation, spaceflight and large building structure. All in all, the fiber optic sensors meet the features below:

(1) Compact, light weighted and low power consumption. In general, the fiber optic sensors have complicated process technologies involving the semiconductor process, laser processing, precision machining and forming technologies, so as to make sensors smaller or more miniature. Thus, traditional bulk optic components such as beam splitters, combiners, and objective lenses have been rapidly replaced by small-sized fiber devices that enable the sensors to operate on fiber scales, typically $125 \mu \mathrm{m}$ in diameter. Besides, the data carrying bandwidth of fiber optics is so high that hundreds and potentially thousands of sensors can be supported by a single fiber. Fiber optic sensing system could reduce their power consumption to several Watt level, by adopting the power supply with high electro-optical conversion efficiency, refrigerating efficiency and the modulator with low driven voltage.

(2) Adaptation to application requirements in harsh environments. In general, the environment where the fiber optic sensors are used is relatively severe. For example, to name a few, in space launch applications, the fiber optic sensors are required to survive under high impact force (peak acceleration up to $1000 \mathrm{~g}$ ) and/ or high frequency vibration $(1000 \sim 5000 \mathrm{~Hz})$ [8]; Electricity industry requires that the fiber optic sensors have high insulativity; Oil drilling and geological exploration industries require that the sensors are resistant to high temperature (up to $350^{\circ} \mathrm{C}$ ) and pressure (up to $60 \mathrm{MPa}$ ) [9]; Nuclear power stations require that the sensors are highly resistant to radiation.

(3) Reliability and long life span. For example, in some military fields, the sensors have to be very reliable to work and store for a long time, normally more than 10 years 
or even 20 years. In some fields (such as satellite and electricity plant),

optoelectronic elements are required to work continuously for an even longer time.

In comparison with traditional electromechanical or electronic sensors, the fiber optic sensors have relatively high potential to work in hypersonic wind tunnel [10]. Hypersonic wind tunnel experiment technologies are involved to many subjects such as aerodynamic forces, aerothermodynamics, thermal protection of aircraft structures, heatfluid-solid coupling, hypersonic boundary layer, air-breathing propulsion system and light-weighted and high-strength material, and so on. This article has classified and summarized the research status and the representative achievement on the fiber optic sensing technologies, giving special attention to the summary of research status at home and abroad on the popular FPI, FBG and (quasi) distributed fiber optic sensors working in hypersonic wind tunnel environment, and discussed the current problems in special optical fiber sensing technologies. Therefore, this article would be regarded as reference for the researchers in this field.

\section{Working principle of fiber optic sensors}

\subsection{Fabry-Perot Interferometric (FPI) fiber optic sensor}

The FPI fiber optic sensors could be classified into Intrinsic Fabry-Perot Interferometric (IFPI) fiber optic sensors and Extrinsic Fabry-Perot Interferometric (EFPI) fiber optic sensors $[11,12]$ according to their structures. The inside of IFPI fiber optic sensor consists of a section of optical fiber and two mirrors at both ends of this fiber, as shown in Fig. 1a. The resonator inside of EFPI fiber optic sensor consists of two mirrors and air in between, as shown in Fig. 1b. The mirror in FPI fiber optic sensor normally has low reflectivity. The Fresnel reflection is about $R \approx 4.0 \%$ between the end face of fiber and the air, and the backwards-reflected light is also measured. Therefore, the detected interference signal is approximately equal to the cosine type signal of two-beam interference.

With excessive loss neglected, the intensity $I_{r}$ of reflected light from FPI sensor is dependent on the distance $L$ between the two reflecting surfaces, according to Airy function [13]:

$$
I_{r}=\frac{4 R \sin ^{2}(2 \pi L / \lambda)}{(1-R)^{2}+4 R \sin ^{2}(2 \pi L / \lambda)} I_{i},
$$

where $R$ is the reflectivity of the mirrors, and $\lambda$ and $I_{i}$ are the wavelength and intensity of incident light, respectively.

The beam of light source is propagated to the FP cavity along the lead-in / lead-out fiber, among which a fraction of incident light is reflected on the end face of lead-in/ lead-out fiber, forming the first reference beam with the optical intensity $I_{1 r} \approx 4 \% I_{i}$

(a)

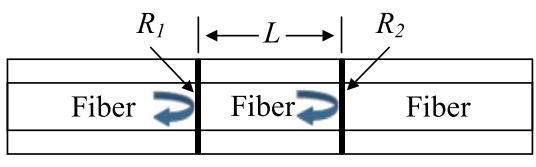

(b)

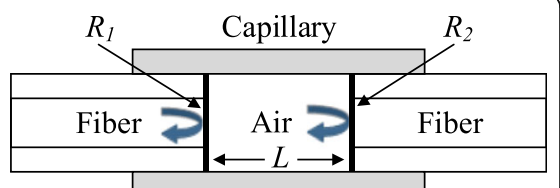

Fig. 1 Basic structures of resonators of (a) Intrinsic and (b) Extrinsic FPI fiber optic sensors 
arising from reflectivity $R \approx 4 \%$. Most transmitted light goes through the FP cavity and then is reflected back, creating the second reference beam $\left(I_{2 r} \approx 3.69 \% I_{i}\right)$. Reflected for three times, the light intensity $I_{3 r}\left(\approx 0.15 \% I_{i}\right)$ is much lower than that of the first one, so the effect of $I_{3 r}$ could be neglected. This means that, it is enough to consider only two reflected beams. Thus, the intensity of reflected light in Eq. (1) could be simplified to [14]

$$
I_{r}=2 R[1-\cos (4 \pi L / \lambda)] I_{i} .
$$

For FPI fiber optic sensor, the reflected light spectrum curve, as well as the fitting based on Eq. (2), is shown in Fig. 2.

As for FPI fiber optic sensor, the wave length of reflection interference light $\lambda$ is mainly dependent on the elasto-optical effect and the thermo-optical effect, with equation shown below [14]:

$$
\lambda=\lambda_{\text {initial }}+\Delta \lambda_{L}+\Delta \lambda_{T}
$$

where:

$$
\begin{aligned}
\Delta \mathcal{\lambda}_{L} & =2 L \varepsilon, \\
\Delta \lambda_{T} & =n \frac{L}{\lambda} \frac{\Delta T}{\Delta L},
\end{aligned}
$$

$\lambda_{\text {initial }}$ is the original wavelength; $\varepsilon, n, \Delta L$ and $\Delta T$ are strain, fiber reflectivity, change in cavity length and change in temperature, respectively.

Equations above represent that FPI fiber optic sensors can be used for multiple parameters sensing, such as temperature, strain and pressure. As FPI fiber optic sensors make use of change in cavity length to pick up the outside parameters, the length of sensing element is dependent on the actual operating requirements, ranging from a few

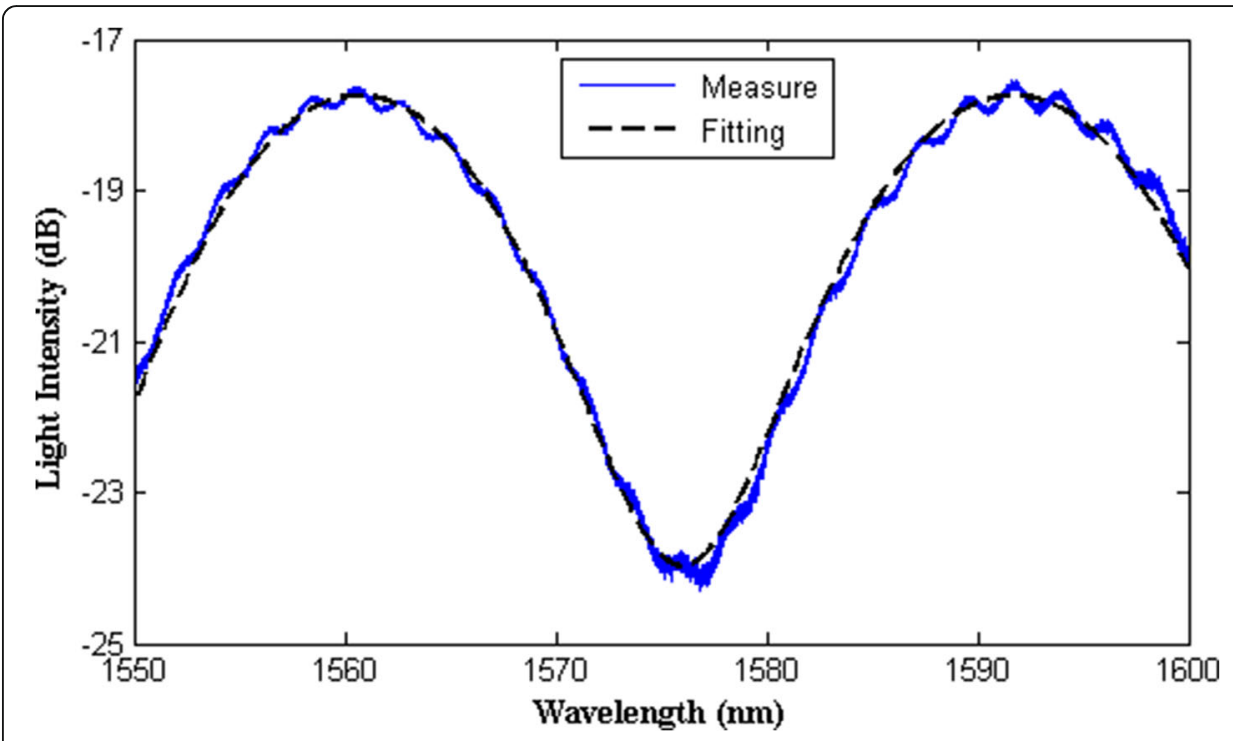

Fig. 2 Reflected light spectrum of FPI fiber optic sensor 
to hundreds of micrometers, able to satisfy different measurement requirements such as high spatial resolution, miniaturization and high sensitivity.

In 1988, Lee, Talyor and others reported on IFPI-based fiber optic sensors [6]. In 1991, Murphy and others reported EFPI strain fiber optic sensors that tested the fatigue property of F15 fighter fuselage by inserting the fiber into a quasi-straight capillary tube and then attaching them onto the fuselage with epoxy resin $[5,15]$. In the same year, Wolthuis used silicon diaphragm as a mirror and a pressure-sensing element, generating EFPI fiber pressure and temperature sensor suitable for medical field [16]. Since 2000, researchers have developed multiple FPI fiber optic sensors by adopting laser welding, arc welding, micro-machining and others, making the FPI fiber optic sensors more reliable and stable for a long time. Up to now, FPI fiber optic sensors have been widely adopted to measure the pressure, temperature and strain under such severe conditions as oil wells, the dynamic pressure in gas turbine engine and transformer with high voltage and power, and the pressure of element implanted in human body and others $[7,17]$.

Since the beginning of the 1990s, universities and research institutes in China have started the study on FPI fiber optic sensors, and many of them have been applied to the fields of bridges and oil wells for strain/pressure measurements [18, 19]. Dalian University of Technology has developed a sensing system combining the FPI based pressure sensor $[20,21]$ with the distributed temperature sensor, which can reach $0.1 \%$ accuracy for the pressure measurement with a $0-30 \mathrm{MPa}$ working range and $1{ }^{\circ} \mathrm{C}$ accuracy for the temperature measurement in a working range from room temperature to $300{ }^{\circ} \mathrm{C}$; additionally, a resolution of below $1.4 \mathrm{kPa}$ for the pressure measurement and $0.5^{\circ} \mathrm{C}$ for the temperature measurement has been realized. And this sensing system has now been successfully applied in Liaohe and Xinjiang oil wells. Ding etc. at Beijing Institute of Technology [22] demonstrated a miniature fiber-optic sensor working up to $500{ }^{\circ} \mathrm{C}$. Rao etc. at University of Electronic Science and Technology of China [23, 24] fabricated an all-fiber in-line FPI strain sensor working over a temperature range from $20^{\circ} \mathrm{C}$ to $800{ }^{\circ} \mathrm{C}$ by using $157-\mathrm{nm}$ laser micromachining, and linearity and repeatability of the sensor were $\sim 99.92 \%$ and $\sim \pm 0.8 \mu \varepsilon$ over $500 \mu \mathrm{m}$ displacement.

\subsection{Fiber Bragg Grating (FBG) fiber optic sensors}

FBG is one of the optic fiber passive elements rapidly developed in recent years. Using the photo-sensitivity of optic fiber (the outside incident photon and the germanium ion interact with each other, leading to refractive index changed permanently), the FBG establishes a spacious phase grating inside of fiber core, of which period and modulation amplitude of refractive index are constants [18] (Fig. 3), with the grating period normally less than $1 \mu \mathrm{m}$ and the refractive index of fiber core changing in accordance with equation below:

$$
\Delta n(z)=\overline{\delta n}\left[1+v \cos \left(\frac{2 \pi}{\Lambda}\right) z\right]
$$

where $\overline{\delta n}$ is the average growth value of refractive index of fiber core, $v$ is the modulation coefficient of refracive index $(0 \leq v \leq 1), \Lambda$ is the period of uniform grating, and $z$ is the position coordinate of fiber grating in the axial direction.

If the phase-matching conditions are satisfied, the Bragg wave length of grating is 


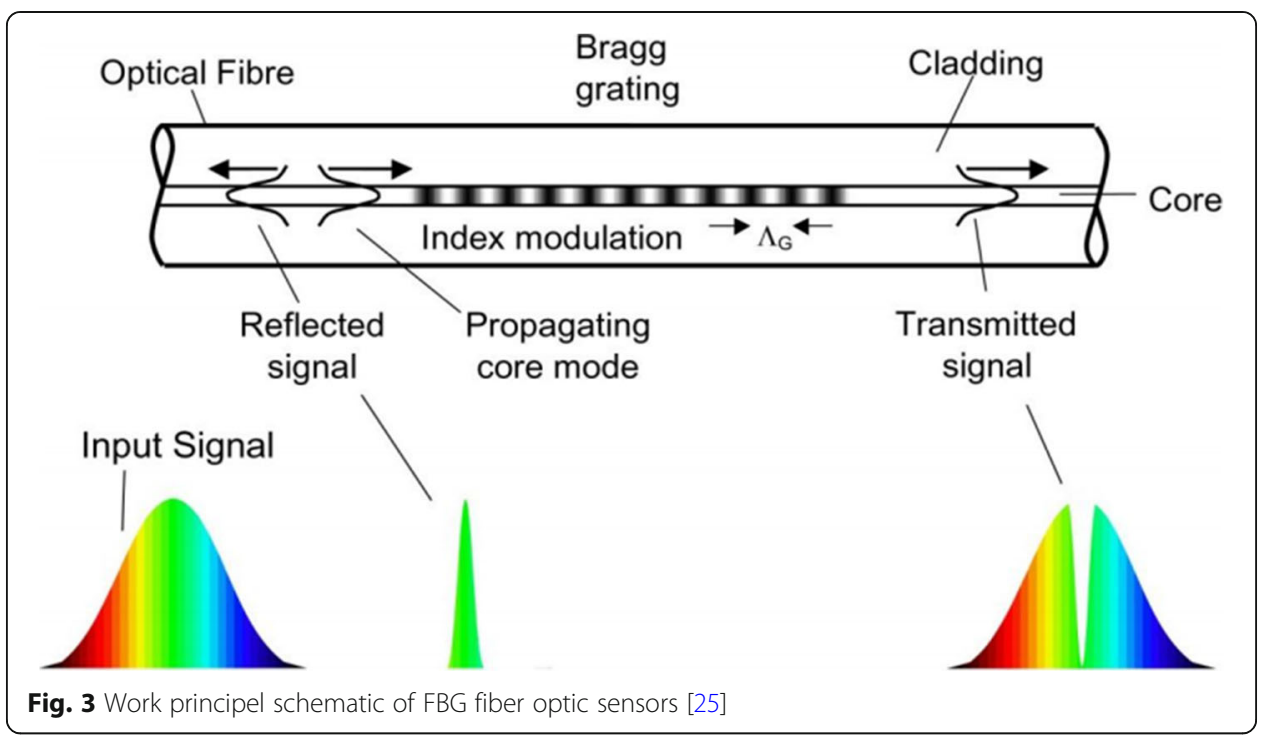

$$
\lambda_{B}=2 n_{e f f} \Lambda
$$

where $\lambda_{B}$ is the Bragg wavelength and $n_{\text {eff }}$ is the effective refractive index of optical fiber.

As one of the reflective filters with fine performance, Bragg grating has reflectivity as high as approximately $100 \%$, with its reflection bandwidth and reflectivity flexibly controlled by changing the writing conditions so as to meet the needing. In addition, the reflected light center wavelength varies with the outside temperature and pressure, with the relationship between the changing quantity and temperature and strain shown below [25]

$$
\frac{\Delta \lambda_{B}}{\lambda_{B}}=\left(\alpha_{f}+\xi\right) \Delta T+\left(1-P_{c}\right) \Delta \varepsilon,
$$

where $\alpha_{f}=\frac{1}{\Lambda} \frac{d \Lambda}{d T}$ is the coefficient of thermal expansion of optical fiber, $\xi=\frac{1}{n} \frac{d n}{d T}$ is the thermal-optical coefficient of optical fiber and $P_{c}=-\frac{1}{n} \frac{d n}{d \varepsilon}$ is the elasto-optical coefficient of optical fiber.

With corresponding sensing structure, FBG fiber optic sensors could measure various parameters such as temperature, strain and pressure. The wavelength in the middle of reflected spectrum of fiber grating is called as peak wavelength, as the reflected spectrum of fiber grating is symmetrical, with the maximum reflectivity at center wavelength. In addition, strain and temperature could drift the wavelength of fiber grating. In other words, the higher the temperature of the strain becomes, the bigger the center wavelength is. As for the fiber grating working in $1550 \mathrm{~nm}$ of band, the center wavelength has the temperature coefficient of approximately $10 \mathrm{pm} /{ }^{\circ} \mathrm{C}$ and the strain coefficient of about $1.2 \mathrm{pm} / \mu \varepsilon$.

In 1978, Hill and others from Communications Research Center Canada achieved the backward -mode coupling FBG [26] in the way that the bi-directional $488 \mathrm{~nm}$ argon ion laser created a standing wave in the germanium-containing fiber through interference, allowing the fiber refractive index to alter periodically along the axial direction. But, due to the limitation of writing method and optical fiber development, Hill grating 
was at low efficiency to prepare and relatively poor in spectrum features. In 1989, Meltz and others adopted $244 \mathrm{~nm}$ UV-light dual-beam holographic exposure technologies to develop FBG [27], providing a practical method to make the FBG. In 1989, while fiber grating technology was being developed to be written on the side of UV light, Morey and others were the first to study the fiber grating temperature and strain sensing features, finding out the center wavelength of fiber grating has good linear relationship with temperature and strain [28]. In 1993, Bell Labs put forward the hydrogen-carrier technique to increase the fiber sensitivity to light [29]. In the same year, Hill also came up with the phase shift mask method to produce the fiber grating [30], which is the most popular way up to now.

Since the early 1990s, FBG sensing technology has been developed in several universities in China, such as Tsinghua University, Chongqing University, Wuhan University of Technology, Harbin Institute of Technology, Tianjin University, Chinese Academy of Sciences and so on. FBG sensors have been applied in many fields, like bridge health monitoring, high temperature and high pressure sensing in oil well and seismic detection [31-34]. Besides, Liu etc. at Shanghai Jiao Tong University demonstrated an ultrahigh resolution FBG strain sensor with a broad frequency range from quasi-static to several hundred hertz, and the sampling rate is up to $500 \mathrm{samples} / \mathrm{s}$, with a strain resolution better than $0.01 \mathrm{n} \varepsilon$ and dynamic range of $149 \mathrm{~dB}$ at $10 \mathrm{~Hz}$ [35].

\section{3 (Quasi) distributed optical fiber sensing technology}

In accordance with the distribution of parameters to be measured, fiber optic sensors are classified into point-based, quasi-distributed and distributed fiber optic sensors. As shown in Fig. 4a, point-based fiber optic sensor has each fiber connected with merely one fiber optic sensor, with sensitive area much less than the length of fiber. For

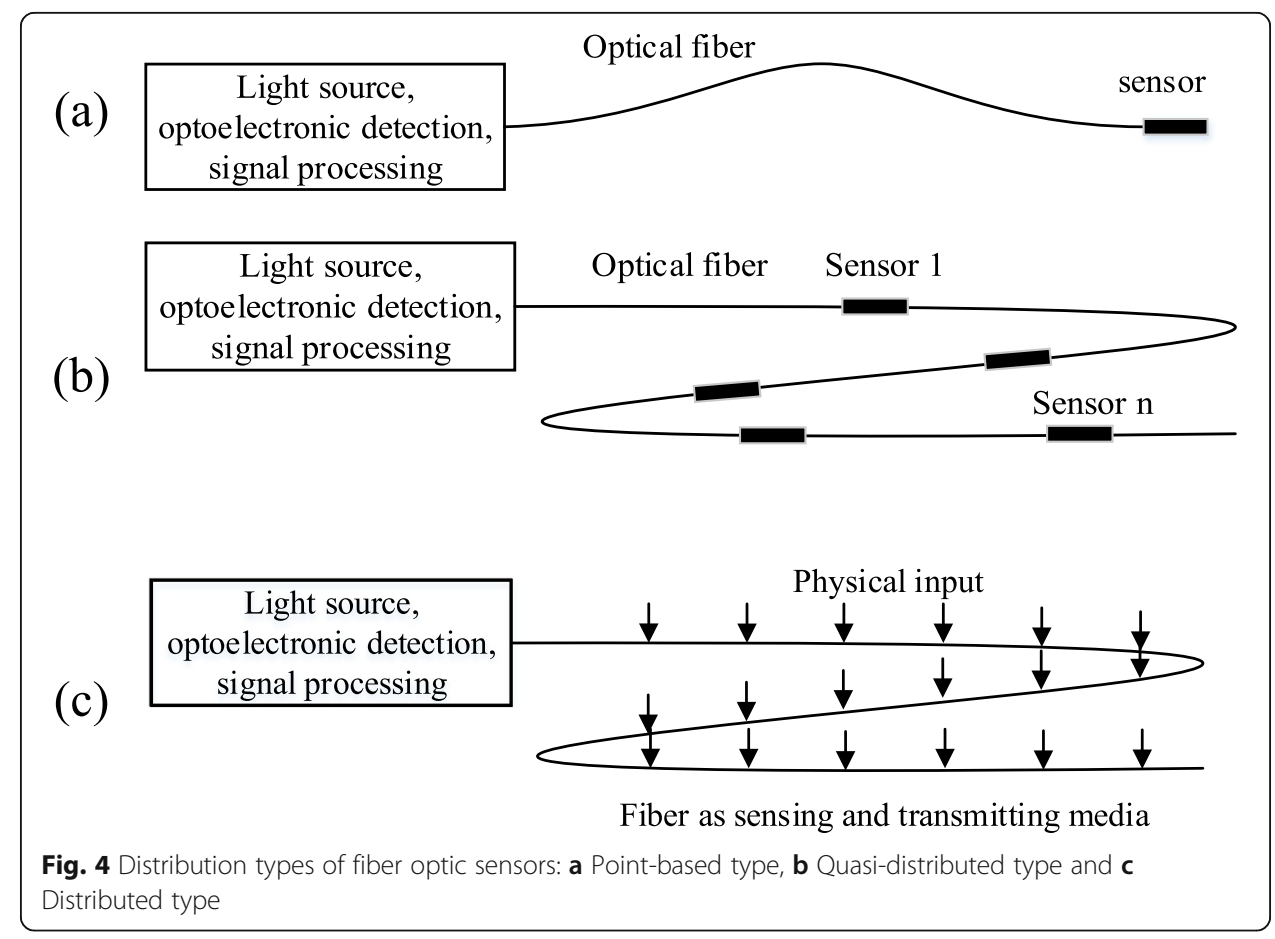


example: the above-mentioned FPI and FBG belong to this kind of sensor. As shown in Fig. 4b, the quasi-distributed fiber optic sensor has each fiber connected with multiple point-based optic fiber sensors, sensing and measuring the parameters at several positions on fiber path. For example: fiber grating sensing matrix [36] and fiber hydrophone matrix [37]. As shown in Fig. 4c, the distributed fiber optic sensor not only has the sensing functions, but also transmits the optical wave signal, picking up the outside parameters continuously arranged along the fiber path. For example: distributed fiber Raman temperature sensor [38] and fiber Brillion temperature / strain sensor [39].

Using of inhomogeneity of the constituent in fiber, the distributed fiber optic sensor could have its refractive index non-uniform in the microcosmic way, featuring long sensing length, simple structure, convenience and high performance cost ratio. As short pulse emitted by the pulsed laser is transmitting in fiber, the change in features (frequency, light intensity and polarization state) of backward scattered light could determine the value of physical quantity to be measured, and the duration of echo could determine the position. The scattering mechanisms used for engineering include Rayleigh scattering [40], Raman scattering [41] and Brillion scattering [42]. Now, it becomes relatively mature that the distributed fiber optic sensing system is with a spatial resolution of $1 \mathrm{~m}$ at least (http://www.sensornet.co.uk, http://www.omnisens.com, http://www.neubrex.com, http://www.ozopics.com). Furthermore, OZ Optics Company in Canada and Neubrex Company in Japan have made the trial sample with $10 \mathrm{~cm}$ spatial resolution [43].

The quasi-distributed fiber optic sensor has a series of FBG point-based sensors laid on one single fiber, increasing the spatial resolution that is normally less than $1 \mathrm{~cm}$ or even dozens of micrometers. The quasi-distributed fiber optic sensors have other advantages: generating very strong light signal and providing very high signal to noise ratio. Therefore, this kind of sensors could obtain higher measuring precision and resolution than the distributed fiber optic sensors. As for the quasi-distributed fiber optic sensors based on FBG (principle shown in Fig. 5), the normal multiplexing technologies are classified into wavelength division multiplexing (WDM) [44] and time division multiplexing (TDM) [45]. In addition, the quasi-distributed fiber optic sensors are highly potential to precisely measure the stress/strain, temperature and others on the model surfaces under hypersonic wind tunnel conditions, because they are highly sensitive to the temperature, strain/stress, vibration and other outside physical quantities,

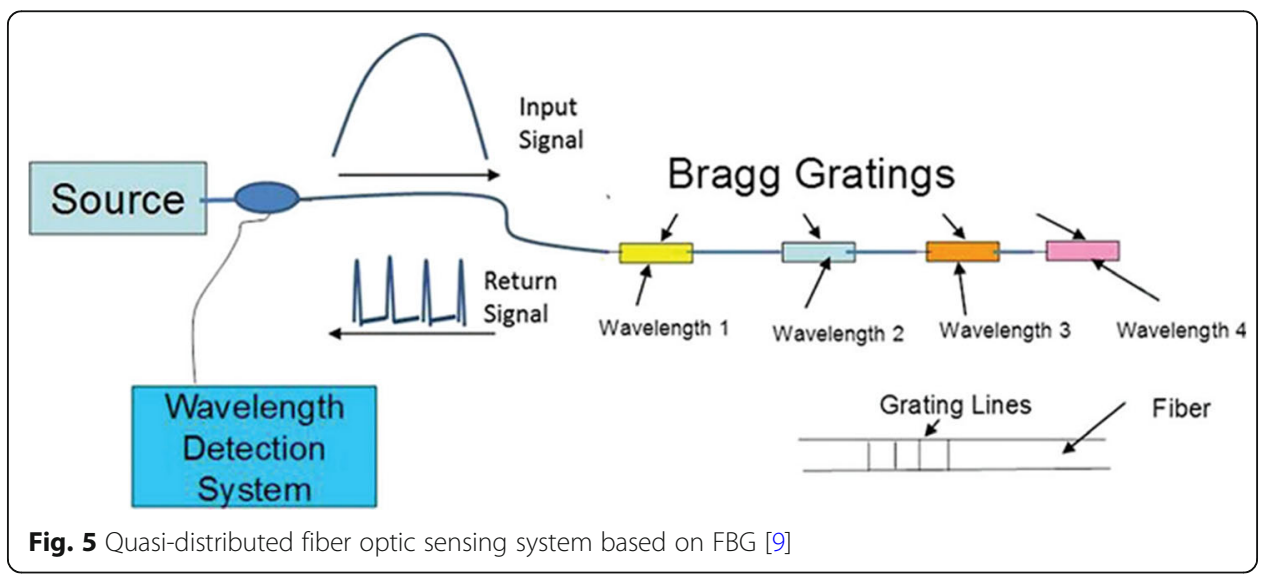


compact, wide dynamic zone, reliable and strong multiplexing capacity of quasidistribution.

Domestic research in the field of (quasi) distributed optical fiber sensing has also made considerable progress. Rao etc. at University of Electronic Science and Technology of China demonstrated an ultra-long-distance distributed sensing system, and the sensing distance was up to $154.4 \mathrm{~km}$ with $5 \mathrm{~m}$ spatial resolution and \pm $1.4^{\circ} \mathrm{C}$ temperature uncertainty [46]. Dong etc. at Harbin Institute of Technology developed a distributed temperature sensor, with $2 \mathrm{~cm}$ spatial-resolution hot-spot detection and $2{ }^{\circ} \mathrm{C}$ temperature accuracy over a $2 \mathrm{~km}$ sensing fiber [47]. Ding etc. at Tianjin University constructed a distributed vibration sensor that can have a dynamic range of $12 \mathrm{~km}$ and a measurable vibration frequency up to $2 \mathrm{kHz}$ with a spatial resolution of $5 \mathrm{~m}$ [48]. Meanwhile, Fan etc. at Shanghai Jiao Tong University developed a distributed vibration sensor that has a measurement range of 40 $\mathrm{km}$, a spatial resolution of $3.5 \mathrm{~m}$, a measurable vibration frequency up to $600 \mathrm{~Hz}$, and a minimal measurable vibration acceleration of $0.08 \mathrm{~g}$ [49]. Zhang etc. at Chinese Academy of Sciences developed an optical reflectometry, and the reflection events can be precisely located in a detection range of $\sim 47 \mathrm{~km}$ with a rangeindependent resolution of $2.6 \mathrm{~mm}$ [50]. Jiang etc. at Wuhan University of Technology developed large-scale FBG arrays made with in-line FBG fabrication, and obtained the reflection spectra of an ultra-weak FBG array with near-identical 3010 FBGs, using a wavelength scanning time division multiplexing scheme [51].

\section{Fabrication process of fiber optic sensor}

With the development of fiber optic sensor, the fabrication process of sensor is a fundamental step to develop the fiber sensor. Besides, the rapid development of miniaturization process provides a new way to fabricate the new generation of miniaturized fiber sensors, as well as a chance for fiber optic sensors to work under harsh environments.

\subsection{FPI fiber optic sensors}

This kind of sensors has not yet batch developed, because traditional micromachining process is very difficult to directly produce on micro-structure of fiber, and accordingly very expensive. The laser miniaturization process, micro / nano fabrication and film technology push the research on new generation of optoelectronic elements (optical communication devices, fiber sensors and electric sensors) by providing the new technical means [52-54]. For example, Rao and others [14, 55, 56] have fabricated FPI sensors based on $157 \mathrm{~nm}$ laser micro-machining process, and the reliability of the sensor could be guaranteed by decreasing the size of sensors and adopting the full-quartz structure, with the process flow shown in Fig. 6.

Figure 7 shows the FPI fiber optic sensors made with this method [57]: two reflectors are parallel with each other and the outside surfaces are well spliced together. Scanned with profilometer, FP cavity respectively has the average roughness of $135 \mathrm{~nm}$ and the root-mean-square value of roughness of $205 \mathrm{~nm}\left(R_{a}\right.$ and $\left.R_{q}\right)$, proving that the reflector on the end of fiber is similar to a mirror. 


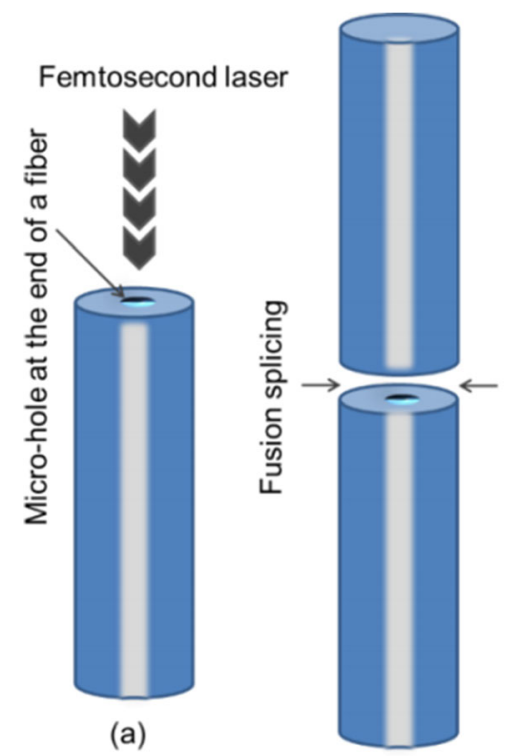

(b)

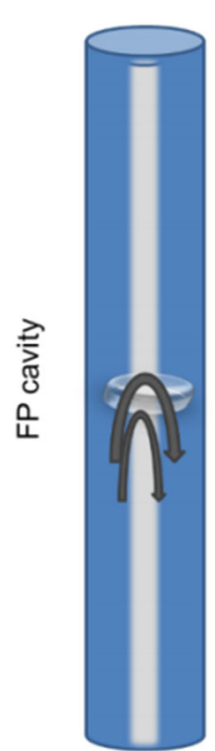

(c)

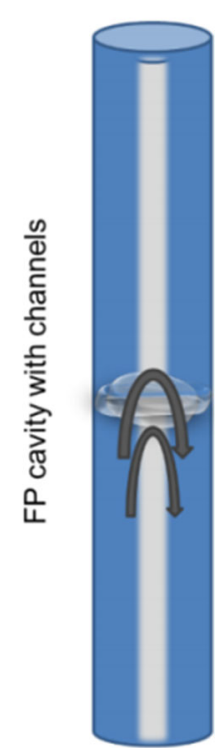

(d)

Fig. 6 Fabrication flow of FPI fiber optic sensors based on laser micro-processing. a A micro hole is made on the readily-cut fiber end by using the pulsed laser, $\mathbf{b}$ and $\mathbf{c}$ The holed fiber is connected to another section of readily-cut fiber by fusion splicing, and at last (d), FP interference cavity is created [56]

\subsection{FBG fiber optic sensors}

Based on the light sensitivity of fiber, the grating could be written into almost all kinds of fibers by adopting proper light source and sensitization technologies. There are many ways to fabricate the fiber grating, mainly two-beam interference method, phase mask method and point-by-point writing method [58, 59]. Among them, the phase mask is the most effective and popular way to fabricate the gratings up to now. By using process with femto-second laser technique, the FBG could work normally at severe conditions such as high temperature, high voltage and high ionizing radiation.

The femto-second laser pulse in transparent glass could induce the permanent change of refractive index of fiber, because when the ultra-short pulse with super-high peak power density is focused on the glass, the instantaneous high energy deposition in the focus zone could induce the breakage of molecular bond due to the multi-photon absorption and the extremely-high non-linear effect, forming the locally traumatic

(a)

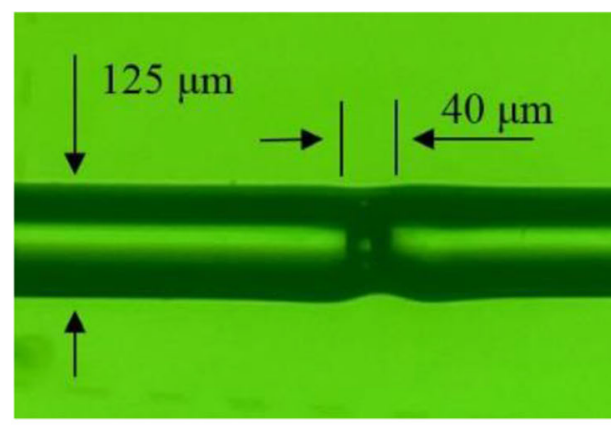

(b)

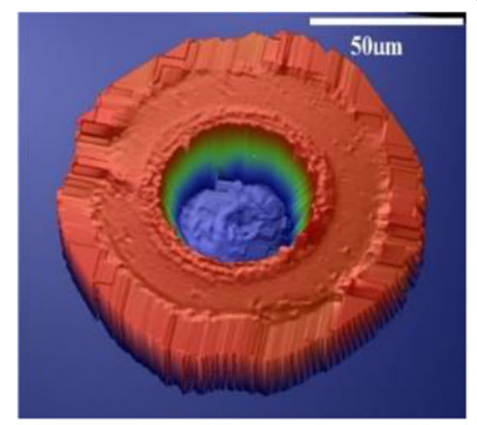

Fig. 7 FPI fiber optic sensors based on laser micro-processing: a FP cavity pictures taken with optical microscope, b Three-dimensional scanning picture of the FP cavity [57] 

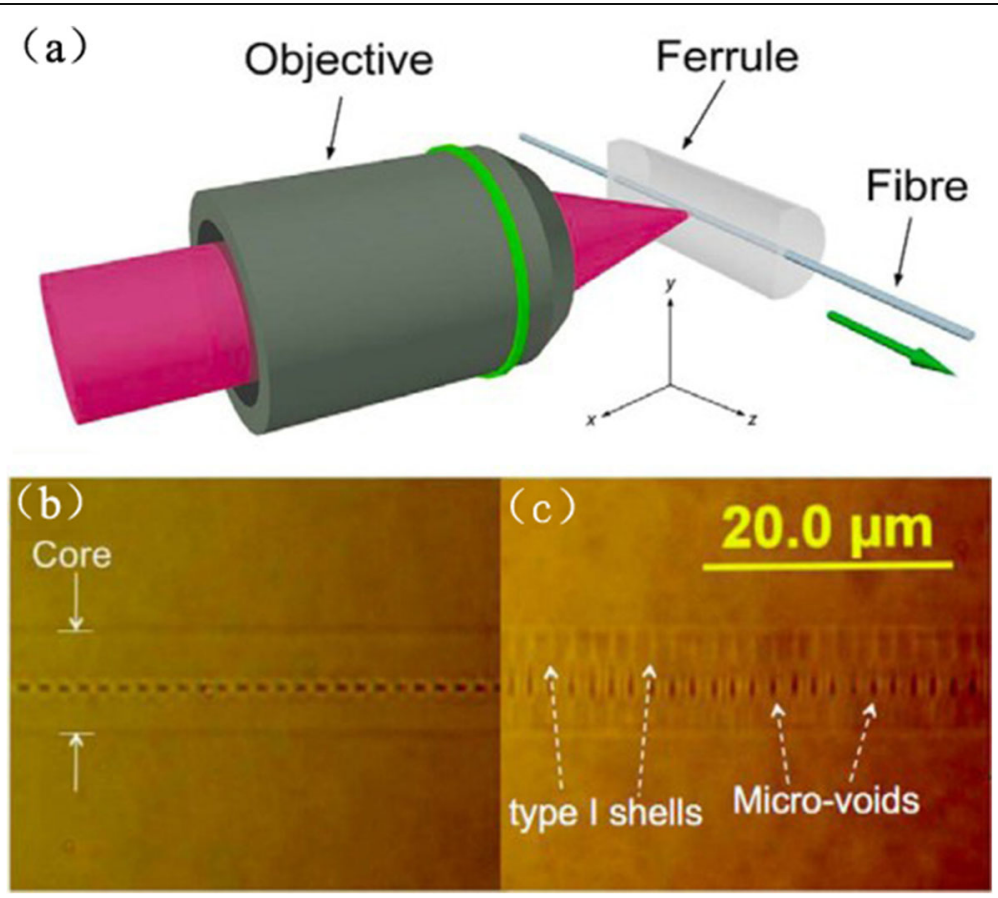

Fig. 8 FBG fiber optic sensor made with femto-second laser technique: a Process schematics, $\mathbf{b}$ and $\mathbf{c}$ Grating micro-structures [60]

change in refractive index. Schematic of typical writing device and micro structure of grating are shown in Fig. 8 [60].

Many studies show that FBG by adopting femto-second laser technologies is not only limited to the quartz fiber, but also used for special waveguide and non-linear crystal fiber that cannot be realized by UV phase mask technique. For example, the sapphire single-crystal fiber FBG [61] fabricated by D. Grobnic and others could have the temperature stabilized at as high as $1500^{\circ} \mathrm{C}$; the full quartz photonic bandgap fiber Bragg grating made by Yuhua Li and others could keep the temperature at $700{ }^{\circ} \mathrm{C}[62]$.

\subsection{Quasi-distributed fiber optic sensors based on FBG}

In order to realize the quasi-distributed fiber optic sensor with large capacity, high density and long distance sensing, and also to put it into practical use by reducing the fabrication cost, the phase mask technique is normally used to repeatedly and online write on the single weak reflective fiber, guaranteeing that the weak-reflection FBG written on the single fiber has the same center wavelength, the reflectivity and bandwidth. With the fabrication principle shown in Fig. 9 [63], this system is composed of laser source, optical system, control system and detection system. Three total-reflection mirrors could adjust the output direction of UV. Then two beams interfere with each other, forming bright and dark strips and modulating the refractive index of the optical fiber core under the corresponding light intensity. During fabrication, the photosensitive fiber is fixed and adjusted with two fiber clamps, so that all the weak-reflection FBG could be written on the single fiber. 


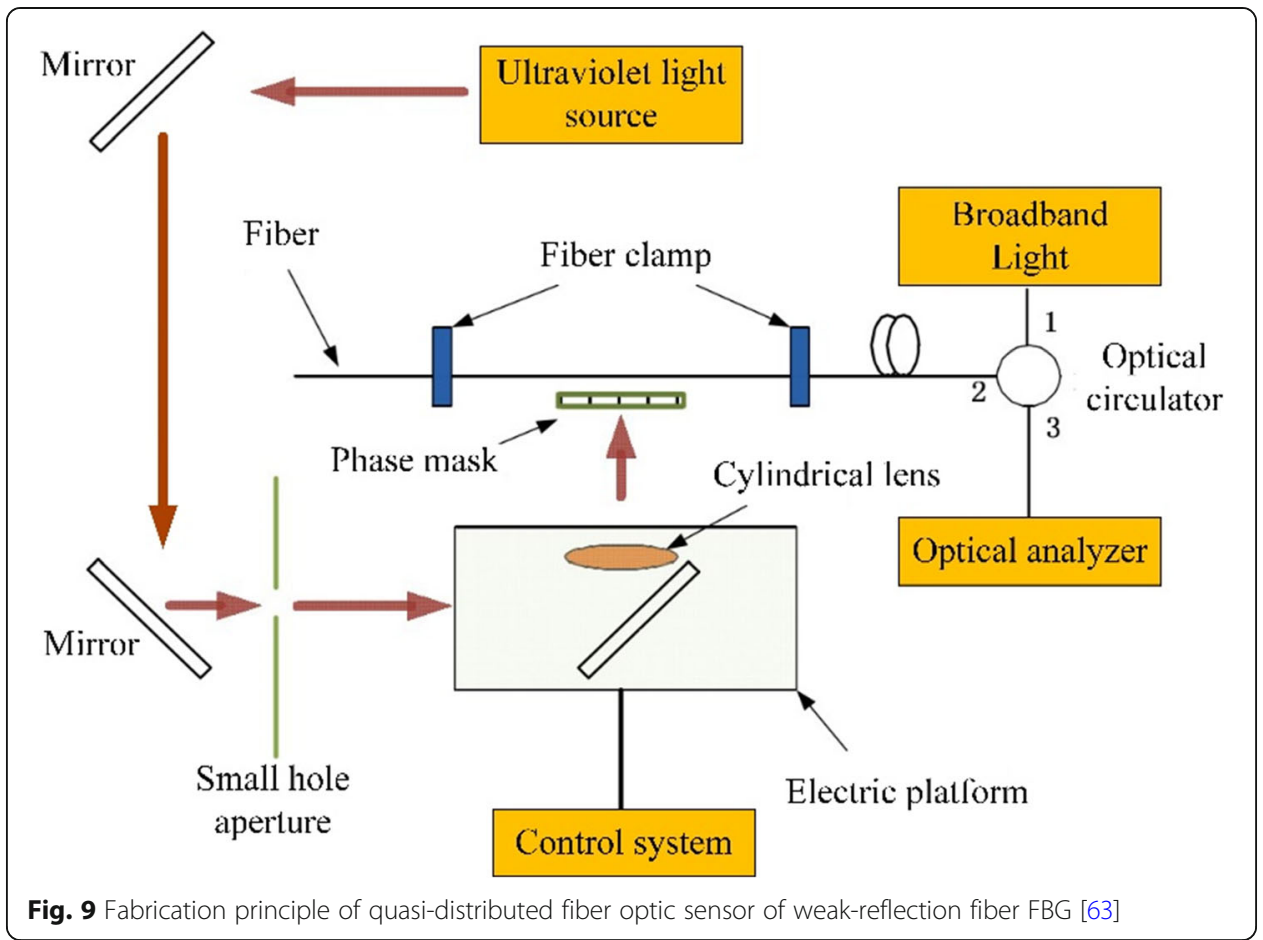

\section{Potential applications in hypersonic wind tunnel environments}

\subsection{Fiber optic strain balance}

The fiber optic strain balances based on fiber optic sensors are newly developed to adapt to the aerodynamic experiment under severe plasma and electromagnetic conditions. At present, the metal resistor strain balances are normally used to measure aerodynamic forces. Over the years, metal resistor strain balances have been developed to a fairly high level, strongly supporting the researches on aerodynamic experiments. However, various wind tunnel experiments have higher requirements on the accuracy of aerodynamic data under harsh environment. In such case, the regular metal resistor strain balance would hardly meet the severe requirement. Just as Dr. Ulrich Jansen said, "the potential to increase the quality of balance data is quite low. We have to place our hope on the new technique of balance, instead of the further optimization of current balance technologies" [64]. Fiber optic sensors bring new thoughts for aerodynamic force measurement because of their high sensitivity, reliability, resistance to electromagnetic interference, corrosion and high-temperature environment.

At present, fiber optic strain balances have two main types: one type of such balance is based on FPI fiber optic sensors, which Arnold Engineering Development Center (AEDC) made a lot effort to design and research $[65,66]$, results showing that fiber optic balances (as shown in Fig. 10) have higher accuracy and anti-interference capacity than the traditional metal resistor stain balance. Based on this principle, China Aerodynamics Research and Development Center (CARDC) developed a prototype of multi-component fiber optic balance [57, 67], as shown in Fig. 11. The strain sensitivity of the FPI sensor was about $0.135 \mu \varepsilon$, and it has been calibrated and evaluated in both Ma4 and Ma8 hypersonic flows. The static calibration accuracy of the FPI balance is better than $0.5 \%$ at full scale design load rang, and good repeatability (better than 1.0\%) of aerodynamic coefficients were 


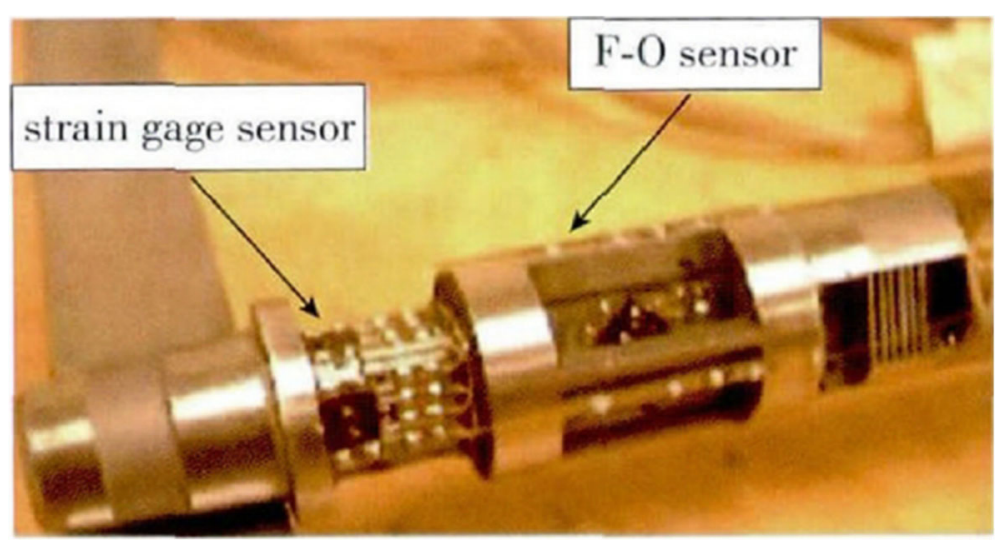

Fig. 10 AEDC fiber optic strain balance [65]

obtained during wind tunnel runs. The test results have been summarized in Table 1. The other type of fiber optic strain balance is based on FBG fiber optic sensor, with the shift of FBG reflected wavelength to pick up the strain. Shenyang Aerospace University developed a five-component fiber grating balance of aerodynamic force measurements in low speed wind tunnel, and its strain sensitivity is estimated to be $0.83 \mu \varepsilon$, and has the same accuracy as the conventional strain balance (better than $0.3 \%$ ) $[68,69]$.

The main factors limiting the fiber optic strain balance performance are the installation quality of optic strain gauge and the thermal output of balance, with the thermal gradient as key factor to affect the axial force measurement. Therefore, proper thermal-insulation techniques should be taken to decrease the temperature fluctuation. However, for the wind tunnel experiment at high temperature for a long time, temperature compensation for optic fiber balance is a key issue. The conventional way to solve this problem is to use an individual temperature sensor to obtain the temperature and to compensate the temperature effect of strain gauge [70-72]. But, this way is quite unreliable and unrepeatable in the wind tunnel, as the temperature sensor insufficiently analyze the thermal variations occurring within the balance structure, especially for the hypersonic force balance designed to work in a highly fluctuating temperature environment. Therefore, it is

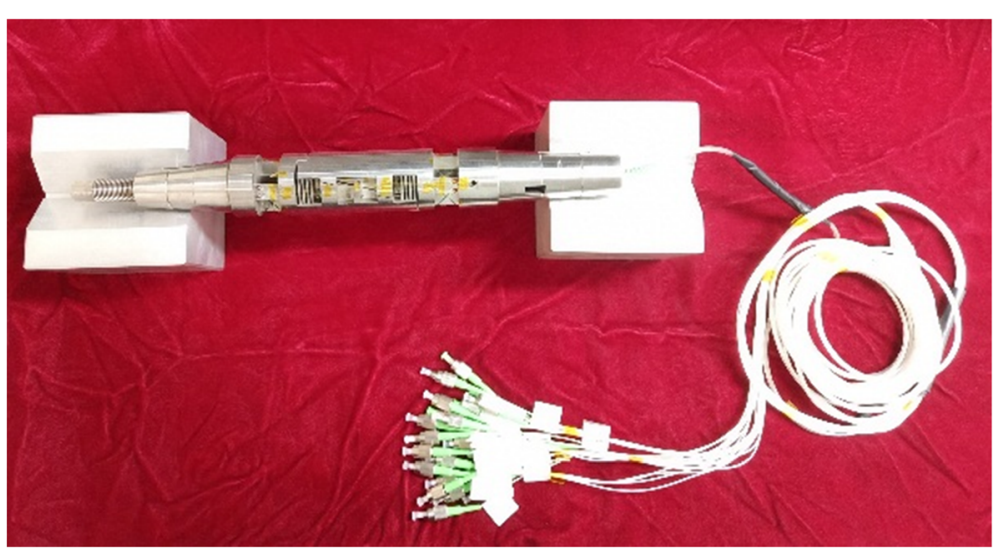

Fig. 11 CARDC fiber optic strain balance 
Table 1 Static calibration and wind tunnel test results of the CARDC fiber optic strain balance [67]

\begin{tabular}{lllll}
\hline Component & $\begin{array}{l}\text { Design } \\
\text { Load }\end{array}$ & $\begin{array}{l}\text { Calibration } \\
\text { Accuracy }\end{array}$ & \multicolumn{2}{l}{ Experimental repeatability } \\
\cline { 5 - 5 } & $360 \mathrm{~N}$ & $0.17 \%$ & $0.85 \%$ & Condition 2 $^{\mathbf{b}}$ \\
\hline$F_{A}$ & $700 \mathrm{~N}$ & $0.30 \%$ & $0.58 \%$ & $0.83 \%$ \\
$F_{N}$ & $\pm 48 \mathrm{~N} \cdot \mathrm{m}$ & $0.33 \%$ & $0.88 \%$ & $0.88 \%$ \\
$M_{z}$ & &
\end{tabular}

${ }^{\mathrm{a}}$ Freestream Mach number $\mathrm{Ma}=3.974$, total temperature $\mathrm{T}_{0}=287 \mathrm{~K}$, total pressure $\mathrm{P}_{0}=0.4 \mathrm{MPa}$

${ }^{\mathrm{b}}$ Freestream Mach number $\mathrm{Ma}=8.052$, total temperature $\mathrm{T}_{0}=740 \mathrm{~K}$, total pressure $\mathrm{P}_{0}=5.0 \mathrm{MPa}$

suggested by the authors to adopt a mixed FPI structure to simultaneously measure the strain and the temperature [73-76]. Additionally, MEMS process is helpful to keep the sensor in consistent performance and compact structure, to reduce the thermal gradient arising from temperature change. However, this method has to be tested abundantly in spite of the above-mentioned advantages.

\subsection{Strain sensing at high temperature}

The current strain sensors mainly include the electric resistance, piezoresistive, piezoelectric and fiber optic strain gauges. Thermal experiment of hypersonic aircraft structure needs to study precise and reliable strain gauging methods under extreme conditions. Additionally, in the combustors of turbine engines $\left(1300 \sim 1400{ }^{\circ} \mathrm{C}\right)$, hypersonic aircraft engines $\left(\sim 2000^{\circ} \mathrm{C}\right)$ and rocket propellers $\left(\sim 3000^{\circ} \mathrm{C}\right)$, strain sensors are also needed to pick up the instantaneous stress in combustors and turbine blades, learning the combustion status and the operation level. As shown in Fig. 12, commercially available piezoresistive, resistive and piezoelectric sensors are limited to work at $800^{\circ} \mathrm{C}$ or less [77-79].

At the end of the twentieth century, NASA Dryden realized that fiber optic sensors have potential capability to solve the problems occurring to the strain measurement experiments of hypersonic aircraft structure, and comprehensively researched the optic fiber experiment techniques at high temperature. NASA Dryden strain test development is shown in Fig. 13 [80].

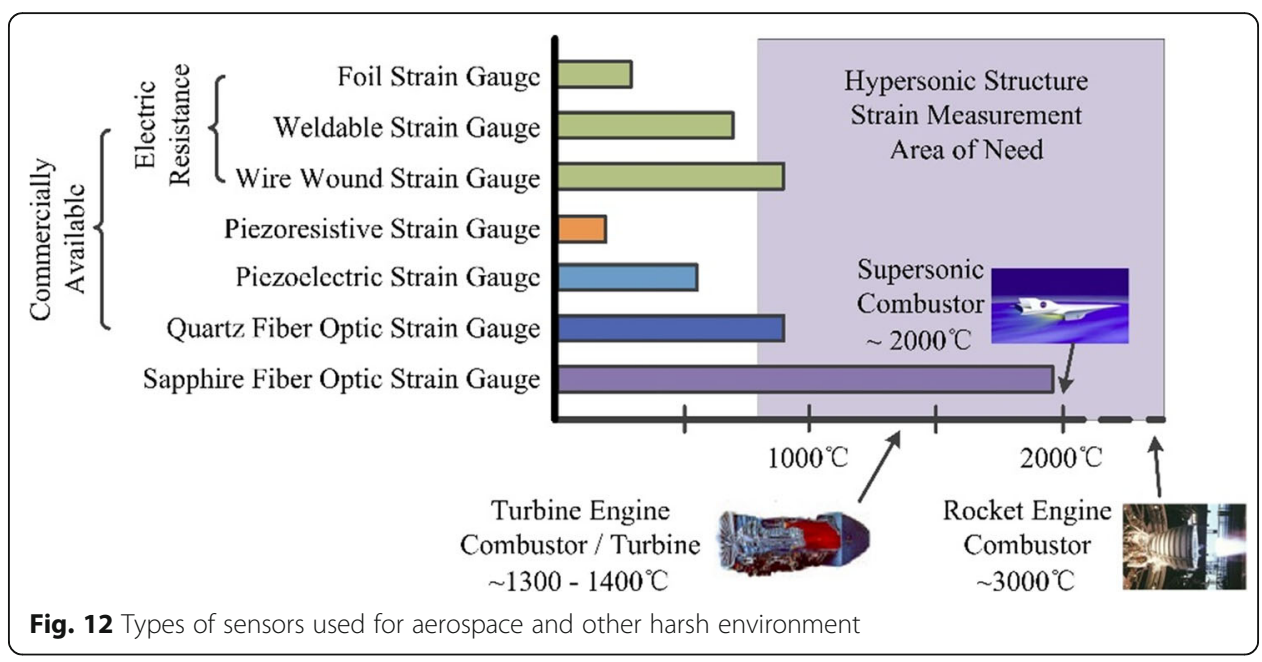




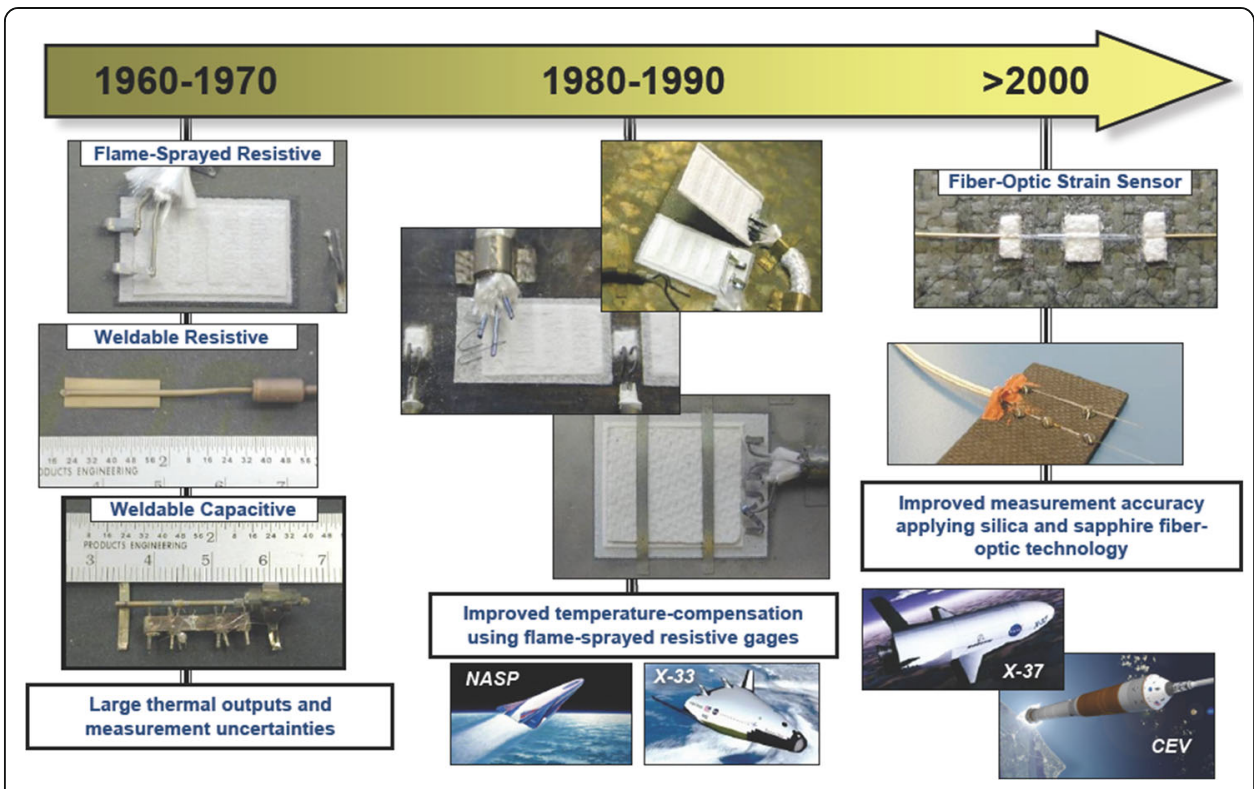

Fig. 13 American NASA Dryden high-temperature strain experiment development [80]

NASA Dryden Flight Loads Laboratory (FLL) carried out the following tests: FBG and EFPI strain sensors were mounted on Inconel, $\mathrm{C} / \mathrm{C}$ and $\mathrm{C} / \mathrm{SiC}$ substrate in the way of thermal spraying; verification of fiber optic sensors at conditions of high/ room temperature; static thermal combined load; ground thermo-structural experiment and flight experiment; development of portable high-temperature fiber experiment system for the ground simulation experiment and the flight experiment [81]. In 2003, at the thermo-structural experiment on C/C Aileron control panel of NGLT project, there were 14 EFPI sensors mounted which picked up the temperature up to $900{ }^{\circ} \mathrm{C}$; at the ground thermo-structural experiment on $\mathrm{C} / \mathrm{SiC}$ fuselage wing in NGLT, there were 14 EFPI sensors mounted, with sensing temperature beyond $1010^{\circ} \mathrm{C}$ [82]. At present, NASA Dryden and Lambda are working together to develop the sapphire fiber strain sensors, with upper limit of temperature required to be $1650^{\circ} \mathrm{C}$ [83].

One difficulty of strain measurements at high temperature is mounting technique of the sensors. Although the adhesive way is easy to use, thermal spraying is still the first choice by NASA Dryden [84]. Figure 14 depicts the thermocouple and the fiber strain sensor mounted in thermal spraying way. In addition, adhesive way not only corrodes the thermocouple or the alloy in strain gauge, but also has potential adhesion failure since the adhesive resin would contract crack. Nevertheless, the thermal spraying technology is suitable for thermal structures of $\mathrm{C} / \mathrm{C}$ and $\mathrm{C} / \mathrm{SiC}$ being mounted with sensors. NASA Dryden has conducted the study on the technologies of sensors mounted onto the various materials, including the surface treatment suitable for base surface and the optimal plasma painting parameters (powder type, power, movement speed and spraying distance), the optical selection of the most practical adhesives and the improvement of the way to protect the fragile sensors during the severe mounting procedures. 

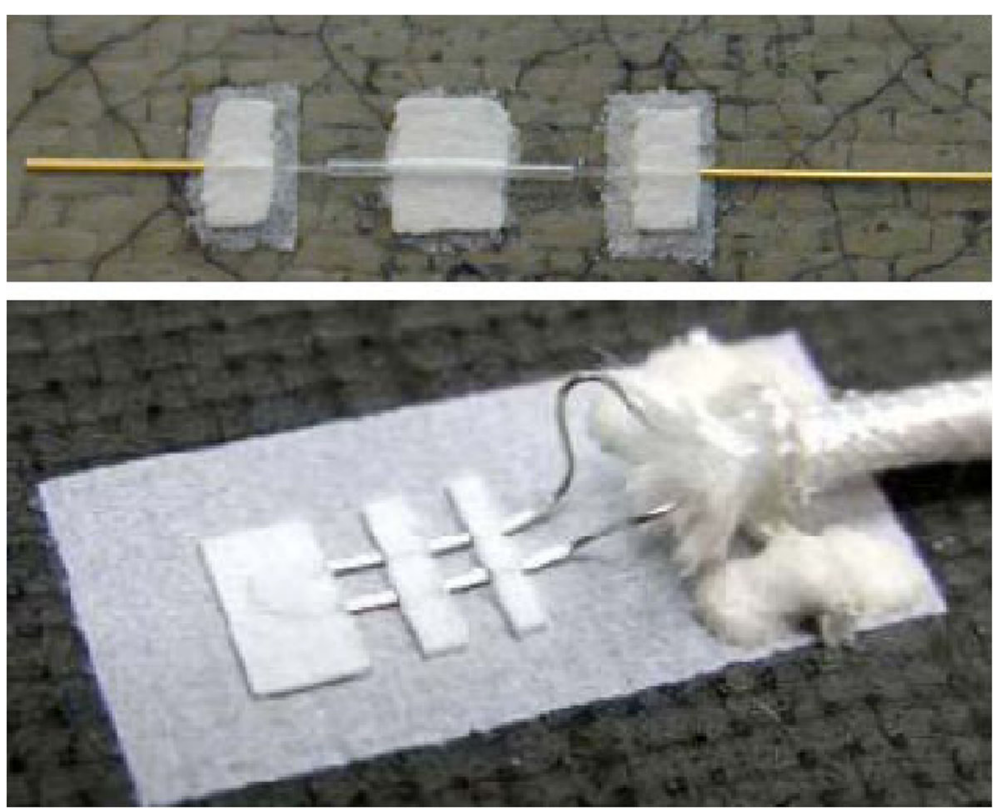

Fig. 14 Sensors mounted through thermal spraying [84]

\subsection{Fiber optic high temperature sensing}

As hypersonic aircrafts fly at high speed in the atmosphere for a long time, generating quite high dynamic pressure and aerothermodynamic heating effect, special heat protective measures should be taken to make sure the thermal structures of control panel of hypersonic aircrafts work properly under hot flying conditions. An essential step in the development of hypersonic aircraft is to precisely measure the surface temperature of key components under the ground wind tunnel simulated thermal conditions, and then to develop a reliable thermal protection system. Unrelated to the electronic signals and the resistance to electromagnetic interference, radiation and high temperature, the quartz and sapphire fiber sensors show their advantages in severe environment.

Figure 15 shows the heat-resisting sensing system made of sapphire fiber. With a section of sapphire fiber melted onto the tail of quartz fiber, there is a refractive index difference between them, creating the first mirror of quartz fiber sensor; the second mirror is created between the other end of sapphire fiber and the air. The refractive index and the length of sapphire fiber could vary with the outside temperature, accordingly changing the length of optical chamber in fiber optic sensor. Thus, this sensor picks up the temperature, forming a heat-resisting fiber optic temperature sensor [85].

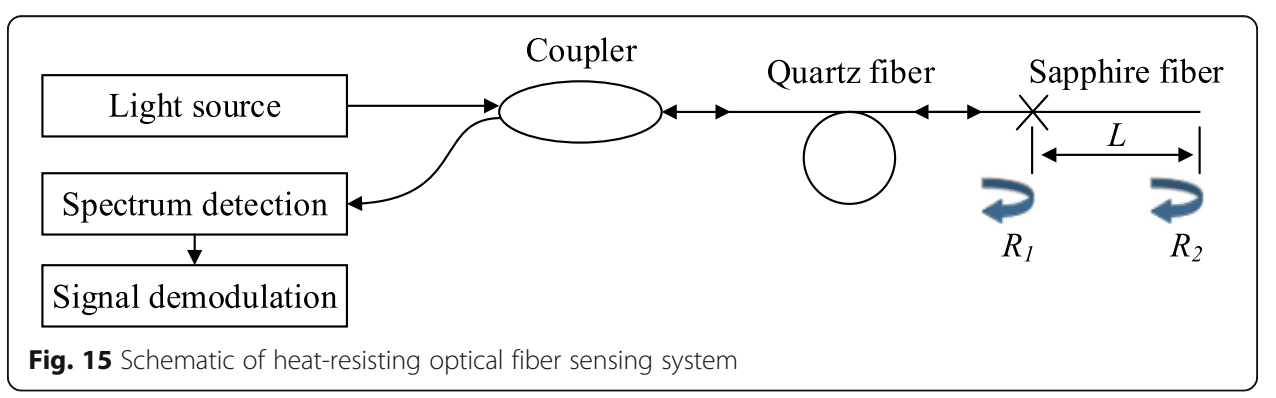


In 2010, J. Wang etc. [86] made a EFPI sensor by using two pieces of sapphire fibers to form an air gap FP chamber, enabling to measure the temperature in the range of $200 \sim 1000^{\circ} \mathrm{C}$. Besides, Y. Zhu etc. [87] made an EFPI sensor by using sapphire chip, enabling to measure the temperature in the range of $230 \sim 1600^{\circ} \mathrm{C}$. In 2015 , Habisreather etc. [88] made a FBG temperature sensor based on sapphire fiber, measuring the temperature as high as $1900^{\circ} \mathrm{C}$, with resolution at $\pm 2{ }^{\circ} \mathrm{C}$.

The temperature sensors based on sapphire fibers have huge market prospect because of simple production and relatively high sensitivity. But, as light transmits in the sapphire fiber at different modes, the mode stability makes it difficult to improve the temperature accuracy. Furthermore, high-power femto-second laser is required to make grating through complicated process, featuring difficult maintenance and high cost. Therefore, this kind of sensors is still in research and cannot be in mass production.

\subsection{Distributed stress/strain/temperature measurement}

As aircraft has complicated structures and works under severe conditions, and therefore increases its possibility of failure, it is necessary to monitor the safety of structures. In comparison with the conventional sensors, the distributed fiber sensors have the advantages of light-weighted, compact, and resistance to electromagnetic interference and to corrosion at high/low-temperature, distributed matrix measurement, effective

Table 2 Research cases of distributed fiber optic sensors being applied to aircrafts [25, 89-93]

\begin{tabular}{|c|c|c|c|}
\hline $\begin{array}{l}\text { Country/ } \\
\text { Region }\end{array}$ & $\begin{array}{l}\text { Applied } \\
\text { model }\end{array}$ & Monitoring position & Achievement \\
\hline \multirow[t]{5}{*}{ USA } & $\begin{array}{l}\text { Predator B } \\
\text { UAV }\end{array}$ & Wing skin structure & $\begin{array}{l}\text { The real-time wing skin shapes are provided } \\
\text { so as for aircraft to obtain the best aero- } \\
\text { dynamic performance. }\end{array}$ \\
\hline & F-15 fighter & Aircraft structure & $\begin{array}{l}\text { Real-time supervision of fatigue performance } \\
\text { of aircraft fuselage }\end{array}$ \\
\hline & Boeing 777 & Aircraft structure & \\
\hline & $x-33$ & Liquid - hydrogen tank structure & $\begin{array}{l}\text { Real-time reflection of liquid-hydrogen tank } \\
\text { structure and the insulating layer structure. }\end{array}$ \\
\hline & F-35 fighter & Main structure of wing & \\
\hline \multirow[t]{3}{*}{ EU } & $x-38$ & Aircraft structure & $\begin{array}{l}\text { Able to measure the space temperature } \\
\text { distribution and the strain of high-load struc- } \\
\text { tures, and estimate the residual life of main } \\
\text { structures of aircraft. }\end{array}$ \\
\hline & $\begin{array}{l}\text { Some micro } \\
\text { aircraft }\end{array}$ & $\begin{array}{l}\text { Low Reynolds number in wind tunnel } \\
\text { and physical parameters when aircraft } \\
\text { is descending. }\end{array}$ & $\begin{array}{l}\text { Able to simultaneously measure the } \\
\text { aerodynamic load, instantaneous model } \\
\text { position, wing deformation and distribution of } \\
\text { flow field. }\end{array}$ \\
\hline & $\begin{array}{l}\text { A340 air } \\
\text { liner }\end{array}$ & Aircraft structure & $\begin{array}{l}\text { Able to record the cyclic stress load imposing } \\
\text { onto the structure to monitor the fatigue } \\
\text { strength of aircraft. }\end{array}$ \\
\hline \multirow[t]{2}{*}{ Japan } & $\begin{array}{l}\text { Some } \\
\text { aircraft }\end{array}$ & Aircraft rubber grating & $\begin{array}{l}\text { Able to integrate the damage supervision and } \\
\text { the location based on the sensing network. }\end{array}$ \\
\hline & $\begin{array}{l}\text { HOPE-X } \\
\text { space } \\
\text { shuttle } \\
\text { model }\end{array}$ & Aircraft structure & $\begin{array}{l}\text { Able to monitor the temperature distribution } \\
\text { of aircraft model }\end{array}$ \\
\hline Spain & A380 airline & $\begin{array}{l}\text { Inflected plate of composite on } \\
\text { fuselage }\end{array}$ & $\begin{array}{l}\text { This sensor is used to detect if composite of } \\
\text { aircraft is damaged and the sticking is failed. }\end{array}$ \\
\hline
\end{tabular}


multiplexing and so on. The distributed fiber optic sensors not only measure the load, the temperature and the strain to reflect the real-time running state of machine, but also monitor the strain, the vibration and other parameters of key structures to judge the property, extent and position of damage on some component. Additionally, the distributed fiber optic sensors have the multiplexing on one fiber, significantly dropping the additional weight and wiring requirements. Studies on optical fiber sensing technologies in Europe and the USA are earlier than that in China by a few of decades, with the USA being one of the earliest countries to apply the distributed optic fiber sensors to the military aircrafts, making great contribution to this research. Table 2 lists the oversea research cases of typical distributed sensors being applied to aircrafts.

Taken the example of experiments on Predator B UAV, the deformation of aircraft wing is tested through high-density and weak-reflection FBG on the basis of OFDR. Figure 16 shows that the sensing fibers are laid on the fuselage and the wings, and 10 standard loads are imposed on the wing and the center fuselage. Then, the wing load and the displacement are respectively measured by using the laser system and the fiber sensing system. The measured results show the tip of wing has maximum displacement at $7.62 \mathrm{~cm}$, with measurement error at $2.8 \%$; after the multiple flight tests, both sides of the wing are deformed in the same way, and the measured results respectively with fiber and conventional strain gauge are basically the same with each other.

\section{Summary and outlook}

Because the advanced sensing technique is in big demand under environment of hypersonic wind tunnel, this article has classified and summarized the research status and the representative achievement on the fiber optic sensing technologies, giving special attention to the summary of research status at home and abroad on the popular FPI, FBG and (quasi) distributed fiber optic sensors working in hypersonic wind tunnel environment, and discussed the current problems in special optical fiber sensing technologies.

Lots of study on these optical fiber sensing technologies have been carried out, and some achievements have been achieved on the manufacturing process, high temperature sensing, multi-channel multiplexing and distributed sensors under environment of hypersonic wind tunnel. Facing the harsh and complex application environment, specified optical fiber sensing technique is still in development, with the following items to be further studied:

(a)

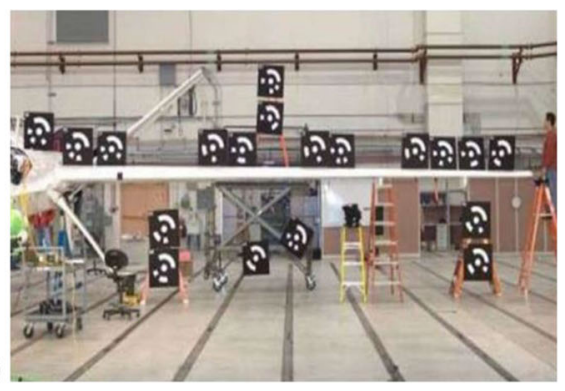

(b)

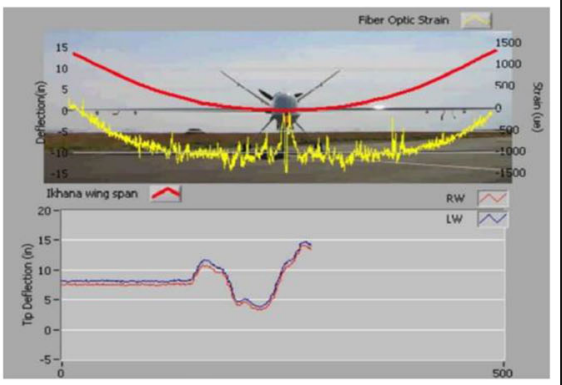

Fig. 16 Tests on Predator B UAV, (a) Test pictures and (b) Test results, with yellow data showing the measured results of fiber strain and red data showing the displacement of wing [91] 
(1) Sensor fabrication and packaging technologies: it is needed to design sensors with more robust structures, higher sensitivity and stronger adaptability to environment.

(2) Multi-parameters cross sensitivity technologies: through the design of sensing elements and the processing of subsequent signals, the independent parameters, such as strain and temperature, could be accurately measured.

(3) Sensor installation technologies: the way to protect the fragile sensors during the installation under harsh environment should be improved.

(4) High-temperature sensing technologies: although having very optimal application prospects, the high-temperature sensors based on sapphire fibers have such problems as transmission mode, stability and reliability, hard to practically apply to engineering.

(5) Distributed sensing space resolution and capacity: the multiplexing quantity limitation of sensing unit should be solved with the distributed sensing systems and the multiplexing methods.

In conclusion, featuring high density, high precision and multiple parameters, the large-scale optical fiber sensing system is the trend to develop the test technologies in hypersonic wind tunnel, but the current achievements are lagged far behind the complex needing to apply in hypersonic wind tunnel. Therefore, the optical fiber sensing system is still needed to be deeply and profoundly studied.

\begin{abstract}
Abbreviations

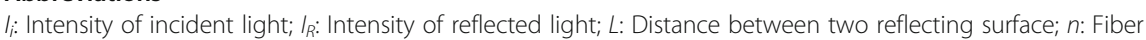
reflectivity; $P_{c}=-\frac{1}{n} \frac{d n}{d \varepsilon}$ : Elasto-optical coefficient of optical fiber; $R$ : Reflectivity of the mirrors; $v$ : Modulation coefficient of refracive index; $z$ : Position coordinate of fiber grating in the axial direction; $a_{f}=\frac{1}{\Lambda} \frac{d \Lambda}{d T}$ : Coefficient of thermal expansion of optical fiber; $\xi=\frac{1}{n} \frac{d n}{d T}$ : Thermal-optical coefficient of optical fiber; $\varepsilon$ : Strain; $n_{\text {eff. }}$ Effective refractive index of optical fiber; $\lambda$ : Wavelength of incident light; $\lambda_{B}$ : Bragg wavelength; $\lambda_{\text {initial: }}$ Original wavelength of incident light; $\Lambda$ : Period of uniform grating; $\Delta L$ : Change in cavity length; $\Delta n(z)$ : Change of refractive index of fiber core; $\Delta T$ : Change in temperature; $\Delta \lambda_{B}$ : Wavelength change of Bragg wavelength; $\Delta \lambda_{L}=2 L \varepsilon$ : Wavelength change of incident light due to strain; $\Delta \lambda_{T}=n \frac{L}{\lambda} \frac{\Delta T}{\Delta L}$ : Wavelength change of incident light due to temperature; $\overline{\delta n}$ : Average growth value of refractive index of fiber core
\end{abstract}

Acknowledgements

Not applicable.

\title{
Authors' contributions
}

$\mathrm{HQ}$ reviewed the literature, and was a major contributor in writing the manuscript. FM carried out experiments regarding the fiber optic balance. YY reviewed and revised the manuscript. All authors read and approved the final manuscript.

Funding

This work was financially supported by the National Natural Science Foundation of China (NSFC) (Project Nr: 2012YQ25002, 11802329).

Availability of data and materials

Not applicable.

Competing interests

The authors declare that they have no competing interests.

\section{Author details}

${ }^{1}$ Hypervelocity Aerodynamics Institute, China Aerodynamics Research and Development Center, Mianyang 621000, Sichuan Province, China. ${ }^{2}$ China Aerodynamics Research and Development Center, Mianyang 621000, Sichuan Province, China.

Received: 17 December 2019 Accepted: 16 March 2020

Published online: 24 April 2020

References

1. Bucare JA, Dardy HD, Carome E (1977) Fiberoptic hydrophone. J Acoust Soc Am 62(5):1302-1304 
2. Nash PJ (1996) Review of interferometric optical fiber hydrophone technology. IEEE P Rador Sonar Nav 143(3):204-209

3. Nash PJ, Cranch GA, Hill DJ (2000) Large scale multiplexed fiber-optic arrays for geophysical applications. In: Proceedings of industrial sensing systems, vol 4202. International Society for Optics and Photonics, Boston, pp 55-65

4. Lee CE, Taylor HF (1988) Interferometric optical fiber sensors using internal mirrors. Electron Lett 24(4):193-194

5. Murphy KA, Gunter MF, Vengsarkar AM et al (1991) Quadrature phase-shifted extrinsic Fabry-Perot optical fiber sensors. Opt Lett 24(6):273-275

6. Cahill RF, Udd E (1979) Phase-nulling fiber optic gyro. Opt Lett 4(3):93-95

7. Rao YJ (2006) Recent progress in fiber-optic extrinsic Fabry-Perot interferometric sensors. Opt Fiber Technol 12(3):227-237

8. Feng W, Xu B, Fan Y et al (2018) Study on life evaluation technology of fiber optic gyroscope in space application. In: Proceedings of fiber optic sensing and optical communication. Society of Photo-Optical Instrumentation Engineers, Beijing, p 108490Y

9. Yin S, Ruffin PB, Yu FFS (eds) (2008) Fiber optic sensors, 2nd edn. CRC Press, New York

10. Qiu HC, Yang YG, Ran ZL et al (2019) Review on fiber optic sensing technologies applicable for hypersonic wind tunnel experiments. In: Proceedings of advanced sensor systems and application IX. Society of Photo-Optical Instrumentation Engineers, Hangzhou, p 111910R

11. Tsai WH, Lin CJ (2001) A novel structure for the intrinsic Fabry-Perot fiber-optic temperature sensor. J Lightwave Technol 19:682-686

12. Kim SH, Lee JJ, Lee DC et al (1999) A study on the development of transmission-type extrinsic Fabry-Perot interferometric optical fiber sensor. J Lightwave Technol 17:1869-1874

13. Atherton P, Reay N, Ring J et al (1981) Tunable Fabro-Perot filters. Opt Eng 20:806

14. Rao YJ, Ran ZL, Gong Y (2017) Fiber optic Fabry-Perot sensors: an introduction. CRC Press, New York

15. Murphy KA, Gunther MF, Vengsarkar AM et al (1992) Fabry-Perot fiber optic sensors in full scale fatigue testing on F-15 aircraft. Appl Opt 31(4):431-433

16. Wolthuis RA, Mitchell GL, Saaski E et al (1991) Development of medical pressure and temperature sensors employing optical spectrum modulation. IEEE Trans Biomed Eng 38(10):974-981

17. Xu J, Wang X, Cooper KL et al (2006) Miniature temperature-insensitive Fabry-Perot fiber-optic pressure sensor. IEEE Photon Technol Lett 18(10):1134-1136

18. Xiong XC, Zhu Y, Fu YM et al (2007) Fiber Fabry-Perot sensor and its application for monitoring bridge strain. J Chongqing Jianzhu Univ 29(3):48-50 (in Chinese)

19. Jin ZG, Yu QX (2006) Fiber-optic temperature / pressure sensor system for high temperature oil well. Chin J Sensors Actuators 19(6):2450-2452 (in Chinese)

20. Wang Q, Zhang L, Sun C et al (2008) Multiplexed fiber-optic pressure and temperature sensor system for down-hole measurement. IEEE Sensors J 8(11):1879-1883

21. Zhou XL, Yu QX, Peng W (2012) Simultaneous measurement of down-hole pressure and distributed temperature with single fiber. Meas Sci Technol 23(8):08512

22. Ding WH, Jiang Y (2013) Miniature photonic crystal fiber sensor for high-temperature measurement. IEEE Sensors J 14(3):786-789

23. Rao YJ, Deng M, Duan DW et al (2007) Micro Fabry-Perot interferometers in silica fibers machined by femtosecond laser. Optic Express 15(21):14123-14128

24. Ran ZL, Rao YJ, Liao X (2009) Self-enclosed all-fiber in-line etalon strain sensor micromachined by 157-nm laser pulses. J Lightwave Technol 27(15):3143-3149

25. Mihailov SJ (2012) Fiber bragg grating sensors for harsh environments. Sensors 12:1898-1918

26. Hill KO, Fujii Y, Johnson DC et al (1978) Photo-sensitivity in optical fiber waveguides: application to reflection filter fabrication. Appl Phys Lett 32(10):647-649

27. Meltz G, Morey WW, Glenn WH (1989) Formation of bragg gratings in optical fiber by a transverse holographic method. Opt Lett 14(15):823-825

28. Morey WW, Meltz G, Glenn WH (1989) Bragg-grating temperature and strain sensors. In: Proceedings of OFS' 89, Paris, France, vol 1989, pp 526-530

29. Lemaire PJ, Atkins RM, Mizrahi $V$ et al (1993) High-pressure $\mathrm{H}_{2}$ load as a technique for achieving UV photosensitivity and thermal sensitivity in $\mathrm{GeO}_{2}$ doped optical fibers. Electron Lett 29(13):1191-1193

30. Hill KO (1993) Bragg gratings fabricated in monomode photosensitive optical fiber by UV expose through a phase mask. Appl Phys Lett 62(10):1035-1037

31. Wang YL, Shi B, Zhang TL et al (2015) Introduction to an FBG-based inclinometer and its application to landslide monitoring. J Civ Struct Heal Monit 5(5):645-653

32. Li T, Tan Y, Zhou Z et al (2015) Study on the non-contact FBG vibration sensor and its application. Photonic Sens 5(2): $128-136$

33. Qiao X, Wang Y, Yang $\mathrm{H}$ et al (2015) Ultrahigh-temperature chirped fiber Bragg grating through thermal activation. IEEE Photon Technol Lett 27(12):1305-1308

34. Zhang X, Liu X, Zhang F et al (2018) Reliable high sensitivity FBG geophone for low frequency seismic acquisition. Measurement 129:62-67

35. Chen J, Liu Q, Fan X et al (2016) Ultrahigh resolution optical fiber strain sensor using dual Pound-Drever-Hall feedback loops. Opt Lett 41(5):1066-1069

36. Philip JN, Geoffrey AC, David JH (2000) Large scale multiplexed fiber-optic arrays for geophysical applications. In: Proceedings of industrial sensing systems, vol 4202. Society of Photo-Optical Instrumentation Engineers, Boston, pp 55-65

37. Yu HB, Sun CY, Li QH (2006) Towed line array sonar spearheads submarine detection. Chin Phys 35(5):420-423 (in Chinese)

38. Morita J, Yoshimura T (1995) Analytical characteristics of stimulated Raman scattering in a multimode fiber obtained with an optical time-domain reflectometer. Appl Opt 34(27):6136-6143

39. Naruse $\mathrm{H}$, Tateda M, Ohno $\mathrm{H}$ et al (2002) Dependence of the Brillouin gain spectrum on linear strain distribution for optical time-domain reflectometer-type strain sensor. Appl Opt 41(34):7217-7217

40. Hartog A (1983) A distributed temperature sensor based on liquid-core optical fibers. J Lightwave Technol 1(3):498-509 
41. Dakin J, Pratt D, Bibby G et al (1985) Distributed optical fiber Raman temperature sensor using a semiconductor light source and detector. Electron Lett 21(13):569-570

42. DeMerchant M, Brown A, Bao X et al (1999) Structural monitoring by use of a Brillouin distributed sensor. Appl Opt 38(13):2755-2759

43. Thevenaz L (2010) Brillouin distributed time-domain sensing in optical fibers: state of the art and perspectives. Front Optoelectron China 3(1):13-21

44. Men L (2008) A multiplexed fiber Bragg grating sensors for simultaneous salinity and temperature measurement. J Appl Phys 103(5):156-162

45. Chun WH, Tam HY, Wai PKA et al (2005) Time- and wavelength-division multiplexing of FBG sensors using a semiconductor optical amplifier in ring cavity configuration. IEEE Photon Technol Lett 17(12):2709-2711

46. Jia XH, Rao YJ, Yuan CX et al (2013) Hybrid distributed Raman amplification combining random fiber laser based 2ndorder and low-noise LD based 1st-order pumping. Opt Express 21(21):24611-24619

47. Dong Y, Zhang H, Chen L et al (2012) $2 \mathrm{~cm}$ spatial-resolution and $2 \mathrm{~km}$ range Brillouin optical fiber sensor using a transient differential pulse pair. Appl Opt 51(9):1229-1235

48. Ding Z, Yao XS, Liu T et al (2012) Long-range vibration sensor based on correlation analysis of optical frequency-domain reflectometry signals. Opt Express 20(27):28319-28329

49. Wang S, Fan X, Liu Q et al (2015) Distributed fiber-optic vibration sensing based on phase extraction from time-gated digital OFDR. Opt Express 23(26):33301-33309

50. Zhang L, Pan B, Chen G et al (2017) Long-range and high-resolution correlation optical time-domain reflectometry using a monolithic integrated broadband chaotic laser. Appl Opt 56(4):1253-1256

51. Guo H, Qian L, Zhou Z et al (2016) Crosstalk and ghost gratings in a large-scale weak fiber bragg grating array. J Lightwave Technol 35(10):2032-2036

52. Deng YP, Jia TQ, Leng YX et al (2004) Experimental and theoretical study on the ablation of fused silica by femtosecond lasers. Acta Phys Sin 53(7):2216-2220

53. Fujiwara T, Nakamoto T, Honma T et al (2003) Refractive index change induced by ultraviolet laser irradiations in erbium-doped Tellurite glasses. Electron Lett 39(22):1576-1577

54. Fang QY, Hu XH (2004) Modeling of skin tissue ablation by nanosecond pulses from ultraviolet to near-infrared and comparison with experimental results. IEEE J Quantum Electron 40(1):69-77

55. Ran ZL, Rao YJ, Deng HY et al (2007) Miniature in-line photonic crystal fiber etalon fabricated by $157 \mathrm{~nm}$ laser Micromaching. Opt Lett 32(21):3071-3073

56. Ran ZL, Rao YJ, Liu WJ et al (2008) Laser micromachined Fabry-Perot optical fiber tip sensor for high resolution temperature independent measurement of refractive index. Opt Express 16(3):2252-2263

57. Qiu HC, Yang YG, Min F et al (2019) Hypersonic aerodynamic force balance using micromachined all-fiber Fabry-Pérot interferometric strain gauges. Micromachines 10:316

58. Zhao Y (2007) Principles and application technologies of optical fiber sensors. Tsinghua University Press, Beijing (in (hinese)

59. Jiang Y (2009) Advanced fiber optic sensing technology. Science Press, Beijing (in Chinese)

60. Marshal GD, Williams RJ, Jovanovic N et al (2010) Point-by-point written fiber-Bragg gratings and their application in complex grating designs. Opt Express 18(19):19844-19859

61. Grobnic D, Mihailov SJ, Smelser CW et al (2004) Sapphire fiber Bragg grating sensor made using femtosecond laser radiation for ultrahigh temperature application. IEEE Photon Technol Lett 16(11):2505-2507

62. Li Y, Wang DN, Jin L (2009) Single-mode grating reflection in all-solid photonic bandgap fibers inscribed by use of femtosecond laser pulse irradiation through a phase mask. Opt Lett 34(8):1264-1266

63. Zhang M, Sun Q, Wang Z et al (2012) A large capacity sensing network with identical weak fiber Bragg gratings multiplexing. Opt Commun 285(13-14):3082-3087

64. Jansen U, Quest J (2007) SG Balance improvements are slowing down - Europe cannot wait that long. In: Proceedings of 45th AIAA aerospace sciences meeting and exhibit. American Institute of Aeronautics and Astronautics, Nevada AIAA 2007-351

65. ChandraKishore M, Srihari GK, Rudresh C et al (2005) Aerodynamic load measurements at hypersonic speeds using internally mounted fiber-optic balance system. In: Proceedings of 21st international congress on instrumentation in aerospace simulation facilities. American Institute of Aeronautics and Astronautics, Sendai, pp 119-122

66. Vasudevan B (2005) Measurement of skin friction at hypersonic speeds using fiber-optic sensors. In: Proceedings of $13^{\text {th }}$ international space planes and hypersonic systems and technology, AIAA 2005-3323

67. Qiu H, Min F, Zhong S et al (2018) Hypersonic force measurements using internal balance based on optical micromachined Fabry-Perot interferometry. Rev Sci Instrum 89:035004

68. Li G, Yang B, Li Y (2010) Five-component FBG balance and its measuring method. Chinese patent, CN101806654A

69. Li G, Wang J, Yang B (2016) Fiber grating measuring force balance manufacture application for drag reduction of plasma. Exp Technol Manag 33(11):89-93 (in Chinese)

70. Hereford J, Parker PA, Rhew RD (1999) Impact of thermal gradients on wind tunnel force measurements. In: Proceedings of 37th AIAA aerospace sciences meeting and exhibit. American Institute of Aeronautics and Astronautics, Nevada, p 0309

71. Hereford J, Parker PA, Rhew RD (2004) Development of thermal gradient compensation algorithms and techniques. In: Proceedings of 2nd AlAA international symposium on strain-gauge balances, Hampton, pp 11-21

72. M. Kouzai, T. Shiohara, M. Ueno, Y. Komatsu, T. Karasawa, A. Koike, N. Sudani, Y. Ganaha, M. Ikeda, A. Watanabe (2008) Thermal zero shift correction of strain-gage balance output in the JAXA $2 m \times 2 m$ transonic wind tunnel. JAXA Research and Development Report, No. JAXA-RR-07-034E

73. Pevec S, Donlagic D (2012) Miniature all-fiber Fabry-Perot sensor for simultaneous measurement of pressure and temperature. Appl Opt 51(19):4536-4541

74. Pang C, Bae H, Gupta A et al (2013) MEMS Fabry-Perot sensor interrogated by optical system-on-chip for simultaneous pressure and temperature sensing. Opt Express 21(19):21829-21839 
75. Yin J, Liu T, Jiang J et al (2014) Batch-producible fiber-optic Fabry-Perot sensor for simultaneous pressure and temperature sensing. IEEE Photon Technol Lett 26(20):2070-2073

76. Bae H, Yun D, Liu H et al (2014) Hybrid miniature Fabry-Perot sensor with dual optical cavities for simultaneous pressure and temperature measurements. J Lightwave Technol 32(8):1585-1593

77. Bau HH, de Roojj NF, Kloeck B (1994) Mechanical sensors. In: Göpel W, Hesse J, Zemel JN (eds) Sensors: a comprehensive survey. VCH Verlagsgesellschaft mbH, Weinheim

78. Fraden J (ed) (2003) Handbook of modern sensors, 3rd edn. Springer, New York

79. Watson RB (2008) Bonded electrical resistance strain gages. In: William NS (ed) Handbook of experimental solid mechanics. Springer, Heidelberg

80. Hudson L, Stephens C (2007) Thermal-mechanical testing of hypersonic vehicle structures. In: Proceedings of Hypersonic MURI review meeting, Santa Barbara

81. Stephens C, Hudson L, Piazza A (2007) Overview of an advanced hypersonic structural concept test program. In: Proceedings of FAP annual meeting - hypersonic project, New Orleans

82. Piazza A (2008) Application of high-temperature extrinsic Fabry-Perot interferometer strain sensor. In: Proceedings of Aeronautic Sensors Working Group, Hampton

83. Piazza A, Richards LW, Hudson L (2008) High temperature strain sensing for aerospace application. In: Proceedings of Summer WRSGC, Hampton

84. Piazza A (2008) High temperature instrumentation. In: Proceedings of hypersonic educational initiative, Hampton

85. Wang A, Gollapudi S, Murphy KA et al (1992) Sapphire-fiber-based intrinsic Fabry-Perot interferometer. Opt Lett 17(14): 1021-1023

86. Wang J, Dong B, Lally E et al (2010) Multiplexed high temperature sensing with sapphire fiber air gap-based extrinsic Fabry-Perot interferometers. Opt Lett 35(5):619-621

87. Zhu Y, He Z, Fabin S et al (2005) Sapphire-fiber-based white-light interferometric sensor for high-temperature measurements. Opt Lett 30(7):711-713

88. Habisreather T, Elsmann T, Pan Z et al (2015) Sapphire fiber Bragg gratings for high temperature and dynamic temperature diagnostics. Appl Therm Eng 91:860-865

89. Kazemi A, Ishihara A (2014) Analysis of LPFBG sensor systems for aircraft wing drag optimization. In: Proceedings of SPIE optical engineering \& applications. Society of Photo-Optical Instrumentation Engineers, San Diego, p 92021F-11

90. Bao X, Chen L (2012) Recent progress in distributed fiber optic sensors. Sensors 12:8601-8639

91. Garcia I, Zubia J, Durana et al (2015) Optical fiber sensors for aircraft structural health monitoring. Sensors 15:1549415519

92. Murphy KA, Gunter MF, Vengsarkar AM et al (1991) Fabry-Perot fiber optic sensors in full-scale fatigue testing on F-15 aircraft. Opt Lett 24(6):273-275

93. Murayama H, Kageyama K, Naruse $\mathrm{H}$ et al (2003) Application of fiber-optic distributed sensors to health monitoring for full-scale composite structures. J Intell Mater Syst 14:3-13

\section{Publisher's Note}

Springer Nature remains neutral with regard to jurisdictional claims in published maps and institutional affiliations.

\section{Submit your manuscript to a SpringerOpen ${ }^{\circ}$ journal and benefit from:}

- Convenient online submission

- Rigorous peer review

- Open access: articles freely available online

- High visibility within the field

- Retaining the copyright to your article

Submit your next manuscript at $\boldsymbol{\nabla}$ springeropen.com 